\title{
Development of Flame-Resistant Cotton Fabrics with Casein Using Pad-dry-cure and Supercritical Fluids Methods
}

\author{
SeChin Chang*, Brian Condon, Sunghyun Nam \\ Southern Regional Research Center, Agricultural Research Service, United States Department of Agriculture, New Orleans, USA \\ Email address: \\ sechin.chang@usda.gov (S. Chang), brian.condon@usda.gov (B. Condon), sunghyun.nam@usda.gov (S. Nam) \\ ${ }^{*}$ Corresponding author
}

To cite this article:

SeChin Chang, Brian Condon, Sunghyun Nam. Development of Flame-Resistant Cotton Fabrics with Casein Using Pad-dry-cure and Supercritical Fluids Methods. International Journal of Materials Science and Applications. Vol. 9, No. 4, 2020, pp. 53-61. doi: $10.11648 /$ j.ijmsa.20200904.11

Received: August 6, 2020; Accepted: August 20, 2020; Published: October 16, 2020

\begin{abstract}
Traditional pad-dry-cure (PDC) and supercritical carbon dioxide ( $\mathrm{scCO} 2)$ methods were used to study the effectiveness of cotton fabrics treated with casein from bovine milk and eco-friendly inorganic materials, urea and diammonium phosphate. Trials were completed successfully. Thermogravimetric analysis (TGA), microscale combustion calorimeter (MCC), $45^{\circ}$ angle and vertical flammability (clothing textiles test) and limiting oxygen index (LOI) tests were carried out for the treated cotton fabrics. When the treated fabrics were tested using the $45^{\circ}$ angle flame, the ignited fabrics self-extinguished and left behind a streak of char. Treated higher add-on fabrics were neither consumed by flame, nor produced glowing embers upon self-extinguishing. All untreated cotton fabrics showed limiting oxygen index (LOI) values of about $18 \%$ oxygen in nitrogen. For formulations with casein, urea and diammonium phosphate, LOI values of treated fabrics were $29-40 \%$ oxygen in nitrogen when add-on values for the formulation were $9.5-18.7 \mathrm{wt} \%$. Furthermore, scanning electron microscope (SEM) was employed to characterize the chemical structure on the treated fabrics, as well as, the surface morphology of char areas of treated and untreated fabrics. The results indicate that fabrics treated with casein are flame resistant. The treated fabrics exhibited improved thermal stability, as evidenced by increased ignition times and lower heat release rates. The results of this study show that casein coated flame-resistant fabrics can be readily applied to textile fabrics using a continuous process that is ideal for commercial and industrial applications.
\end{abstract}

Keywords: Supercritical Fluids, Cotton, Flame-Resistant, Thermogravimetric Analysis, Flammability Tests

\section{Introduction}

Cotton is the most comfortable, breathable, and softest of all natural and man-made fibers. Though fiber affects every aspect of our lives, materials made with cotton are flammable. The flammability of cotton is critical not only to cotton clothes or home furnishings, but also for specialized applications encountered in other industries, such as automotive, electronic, hospitality, software, entertainment, food, chemical, etc. For years, scientists have carried out extensive research in order to improve and develop better ways to subdue this property.

To meet fire safety regulations and expand the use of cotton in textile applications that require flame resistance, a significant number of flame-retardant treatments for textiles were developed in the second half of the last century. It is known that flame retardant additives, such as phosphorus, have the capability to enhance the fire resistance of cotton materials. Several reports on organophosphorus flame retardants, or on flame retardants (FRs) in general, contain evaluations of the mechanism of phosphorus substances [1,2]. The action of phosphorus-based FRs, whether chemical or physical action, presents in both the condense phase and in the flame [3-6] including fire inhibition, heat reduction, surface alteration by phosphoric acid containing compounds and char formation. The scientific evidence reveals that phosphorus largely remains in 
the char, which protects the main material against heat and flame $[7,8]$. It is also known that the efficacy of phosphorus is enhanced by materials containing other flame retardant elements. When phosphorus is combined with silica gel [9], or with nitrogen $[10,11]$, the particular mixtures improve the flammability and/or thermal stability of the treated fabrics or reduce the exothermicity of treated fabrics.

Casein is the major fraction of milk protein that is obtained as a co-product during the production of skim milk. Casein is a family of phosphoproteins with a micelle structure. The high concentration of phosphorus and nitrogen present make this material potentially useful for the preparation of flame retardant formative for cotton cellulosic materials [12, 13]. Phosphorus-nitrogen containing urea-derivative compounds have been shown to be better flame retardants than compounds containing either element alone. Diammonium phosphate (DAP) is often used as a flame retardant chemical to yield semi-durable finishes for cotton [14]. It causes a drop in the temperature of combustion of the material, decreases the highest rates of weight loss during combustion and leads to the formation of large amounts of chars. In an effort to make flame retardant cotton fabrics, urea and DAP were used for phosphorus and nitrogen components because they are economically attractive and environmentally friendly compounds. As a non-durable or semi-durable flame retardant, DAP is broadly used for infrequently washed or disposable products [15]. It has been suggested that DAP is the most effective among non-durable and durable flame retardants in delivering flame retardant properties to cellulosic materials and in yielding char [16].

Different methods, including pad-dry-cure (PDC) and inclusion, have been used to incorporate FRs into cotton textiles. Conventional pad-dry-cure is extensively used to incorporate FRs into cotton fabric by dipping the fabric into the FR solution, padding to remove excess solvent, and drying and curing the fabric [17, 18]. Inclusion is an impregnation process achieved when one molecule is non-covalently enclosed within another molecular structure; however, a drawback of this method is the release of molecules due to the re-swelling of cotton fabric with water $[19,20]$. Given its limitations, inclusion is not widely used to incorporate FRs. An alternative method to enclose molecules into fabrics involves the use of a supercritical fluid (SCF). Supercritical fluids (SCF) are widely applied as a media to process biopolymers and synthetic polymers. They provide an alternative technique to modify natural cellulose [21]. SCF are non-toxic, inexpensive, environmentally benign, nonflammable, and are known for their high diffusion in organic matter. Furthermore, SCF can eliminate or reduce the use of organic solvents and water when dyeing or impregnating hydrophobic or hydrophilic compounds into cotton textiles $[22,23]$. A commonly used SCF is supercritical carbon dioxide ( $\mathrm{scCO} 2)$, which has been used for extractions, impregnations, drying, and dyeing fabrics or polymers $[24,25]$. Current scCO2 impregnation studies have not been performed on cotton fabrics treated with molecules having no reactive functional groups, such as the flame retardants reported in this study. Herein, we investigate the use of $\mathrm{scCO} 2$ to impregnate flame retardants into cotton fabric.

Thermal degradation of untreated control and treated fabric samples were studied using thermogravimetric analysis (TGA) in a nitrogen atmosphere to determine char content at $600^{\circ} \mathrm{C}$. The ASTM D2863-09 procedure [26] was used to establish the limiting oxygen index (LOI) values for untreated and treated samples to determine how much oxygen in nitrogen was needed for combustion. Finally, the flammability of fabric samples was assessed using the $45^{\circ}$ angle (clothing textiles test, ASTM D1230-01; 16 CFR 1610) [27] and vertical (ASTM D-6413-11) [28] flammability tests. The surface morphology of the burned areas was examined by scanning electron microscopy (SEM) to understand the burning behavior of each compound.

\section{Experimental}

\subsection{Materials}

Urea (ACS reagent, $99.0-100.5 \%$ ), casein powder (casein from bovine milk, pure powder), and diammonium phosphate dibasic (BioUltra, $\geq 99.0 \%$ ) were obtained from Aldrich chemical company and used without further purification. In the testing experiments, mercerized twill $\left(258 \mathrm{~g} / \mathrm{m}^{2}\right.$, Style 423) cotton fabrics were obtained from Test Fabrics Inc. and used as received. This fabric was desized (starches removed), bleached, and free of all resins and finishes.

\subsection{Pad-Dry-Cure (PDC) Method}

The PDC layering process consisted of two steps, the immersion of the cotton fabrics in the $1.5 \mathrm{wt} \%$ urea-DAP solution, which passed through a roller, immediately followed by immersion of the fabrics in the $1.5 \mathrm{wt} \%$ casein solution, which also passed through a roller. The two steps were repeated for each formulation, without rinsing, for a total of 2, 5, and 10 cycles using a roller speed of $3 \mathrm{~m} / \mathrm{min}$ and a pad pressure of 3 bar $(300 \mathrm{kPa})$. Cotton twill test fabric 423 was bleached, mercerized, and scoured prior to use and coated cotton fabrics were dried at $110^{\circ} \mathrm{C}$ and cured at $140^{\circ} \mathrm{C}$ via a continuous dryer (Mathis, model KTF-S) set to a speed of $2 \mathrm{~m} / \mathrm{min}$. Once removed from the curing dryer, the fabric was immediately placed in a desiccator to cool to room temperature, and its weight was obtained after cooling. All samples were weighed before and after the treatment, and the values were fitted to the equation (1) to obtain add-on percent (or add-on levels):

$$
\text { Add-on }(\%)=\left[\left(\text { weight }_{\text {after drying }}-\text { weight }_{\text {before treatment }}\right) / \text { weight }_{\text {before treatment }}\right] \times 100
$$

\subsection{High Pressure Supercritical Carbon Dioxide (scCO2) Reactor Method}

The supercritical reactor consisted of ultra-high purity carbon dioxide, a series II Prime/Purge pump, and a highpressure series temperature control reactor. The cotton fabrics were immersed in $1.5 \mathrm{wt} \%$ solutions containing various percentages of casein, urea and DAP and drip dried. The 
fabric was then wrapped around a metal wire cage, which prevents the fabric from being entangled with the stirrer and placed into the $\mathrm{scCO} 2$ reactor. They were stirred in $\mathrm{scCO} 2$ in a $2 \mathrm{~L}$ vessel, heating up to $90^{\circ} \mathrm{C}$. Treating in $\mathrm{scCO} 2$ was carried out at $90^{\circ} \mathrm{C}$ for 3 hours under $1800-2000$ psi pressure. Fabric samples were then dried at $100^{\circ} \mathrm{C}$ for $5 \mathrm{~min}$ and cured at $140^{\circ} \mathrm{C}$ for $3 \mathrm{~min}$.

\subsection{Thermal Gravimetric Analysis (TGA)}

Untreated control and treated fabric samples with casein and urea/DAP were tested by thermogravimetric analysis (TGA) for thermal stability (TA Instrument, Q500). Under a continuous nitrogen atmosphere, samples (5-7mg) were analyzed at a heating rate of $10^{\circ} \mathrm{C} / \mathrm{min}$ starting at room temperature and ending at $600^{\circ} \mathrm{C}$.

\subsection{Micro-scale Combustion Calorimeter (MCC)}

The MCC (Govmark, MCC-2) consisted of a sample mounting post with a thermocouple in the post with its tip at the top directly below the sample holder to monitor temperature. A small fabric sample was inserted in a ceramic cup and placed on the sample holder. This assembly was then inserted into a furnace so that everything was inside the furnace. The heat release combustion (HRC) correlated directly to flow rates of the gases involved in the combustion process and to the oxygen concentrations. HRC used oxygen reduction as a determining factor.

\section{6. $45^{\circ}$ Angle, Vertical Flammability and LOI}

All control and treated fabrics were tested for $45^{\circ}$ angle flammability (Govmark Organization Inc.) and LOI (Dynico Inc.). The details of all tests have been described elsewhere $[15,16] .45^{\circ}$ angle flammability and LOI employed standard test specimens, $15 \times 6$, and $13 \times 6 \mathrm{~cm}$, respectively, mounted in the U-shaped metal frames. For the $45^{\circ}$ angle flammability test, the interpretation of the results, such as the time of flame spread in seconds and the ease of ignition, consolidates the fabrics into categories: Class 1, 2 or 3 . In each test, for each fabric, trials were conducted until they yielded the same results twice consecutively and one representative image was reported with its results. The samples of control twill and all treated fabrics were subjected to the vertical flammability and limiting oxygen index tests. Vertical flame tests were performed on strips of fabric $(30 \mathrm{~cm} \times 7.6 \mathrm{~cm})$. In the LOI test, the reported average concentration of percent oxygen of 4 to 7 trials sorted the fabrics into categories: slow burning, self-extinguishing or flammable in air.

\subsection{Scanning Electron Microscope (SEM)}

The morphology of the specimens was examined using a scanning electron microscope (SEM) (Philips, XL 30). The samples were coated with a gold-palladium alloy, and images were taken with an accelerating voltage of $6 \mathrm{keV}$ and a beam current of $0.5 \mathrm{n} \AA$

\section{Results and Discussion}

\subsection{Fabric Treatment}

Cotton fabric was treated with formulations (casein: urea: DAP) using modified pad-dry-cure (PDC) and scCO2 as the impregnation methods. Formulation and percent add on values (wt $\%)$ of 2,5 , and 10-layer coated cotton fabric samples are shown in Table 1. All casein/urea/DAP layer coating solutions were prepared as following: $1.5 \%$ casein solution in deionized water, and $10 \%$ urea and $10 \%$ DAP in deionized water. Formulations of casein with urea and DAP treatment, PDC-1 (2 layers), PDC-2 (5 layers) and PDC-3 (10 layers), showed 6.1, 6.3 and 9.5 add-ons (wt $\%$ ) for cotton fabrics, respectively.

In the supercritical carbon dioxide treatments, the fabrics were soaked in a beaker containing the $1.5 \mathrm{wt} \%$ casein and various concentration of urea-DAP solution $(5 \mathrm{wt} \%$ and $10 \mathrm{wt} \%$ ) for $1 \mathrm{~h}$. The fabric was removed from the beaker, drip dried, and then wrapped around a metal wire cage, which prevented the fabric from being entangled with the stirrer and placed into the $\mathrm{scCO} 2$ reactor. The remaining solution was then poured into the chamber, and the chamber was sealed. Pressure (1500 psi) was applied at a constant temperature of $60^{\circ} \mathrm{C}$ to obtain the desired add-on of formulations of casein with urea and DAP treatment, SC-1, and SC-2, and showed 14.6 and 18.7 add-ons (wt\%) for cotton fabrics, respectively. After being dried and cured, the treated fabrics appeared white in color.

Table 1. Fabric treatment formulations and TGA data for untreated and treated cotton fabrics.

\begin{tabular}{|c|c|c|c|c|}
\hline Sample symbol & Formulations (casein: urea: DAP) - \# of layer & Add-ons (wt\%) & Onset of Degradation $\left({ }^{\circ} \mathrm{C}\right)$ & Char Yield at $600^{\circ} \mathrm{C}(\%)$ \\
\hline Control & N/A & 0 & 330.7 & 13.9 \\
\hline PDC-1 & $(1.5 \%: 10 \%: 10 \%)-2$ layers & 6.1 & 287.7 & 26.9 \\
\hline PDC-3 & $(1.5 \%: 10 \%: 10 \%)-10$ layers & 9.5 & 278.9 & 33.1 \\
\hline $\mathrm{SC}-1$ & $(1.5 \%: 5 \%: 5 \%)$ & 14.6 & $143.8 / 268.8$ & 33.8 \\
\hline $\mathrm{SC}-2$ & $(1.5 \%: 10 \%: 10 \%)$ & 18.7 & $141.6 / 250.5$ & 36.1 \\
\hline
\end{tabular}

\subsection{Thermal Properties}

Thermogravimetric analysis (TGA) measures the change in mass with respect to temperature and was performed to investigate the thermal stability of casein with urea/DAP. A nitrogen atmosphere was used for all tests. Onset temperature is the temperature when weight loss begins. Char percent yield and onset temperature were determined for the treated fabrics 
and are summarized in Table 1. As the add-on increased, char yield increased, and onset temperature decreased. Degradation of various add-ons ( $\mathrm{wt} \%$ ) of casein with urea/DAP treated samples, PDC-1, PDS-2 and PDC-3, along with untreated control twill, are presented graphically in Figure 1. Untreated twill fabric showed an onset of degradation temperature at $330.7^{\circ} \mathrm{C}$, and char residue of $13.9 \%$ of the original weight at $600^{\circ} \mathrm{C}$. The flame retardants lowered the onset point of the textile when compared to the control. Two stages were usually presented in thermal degradation curves of treated fabrics. The degradation of the flame retardants, the chemicals, was first followed by the degradation of main materials, the fabrics. Three stages of weight loss were exhibited with the control

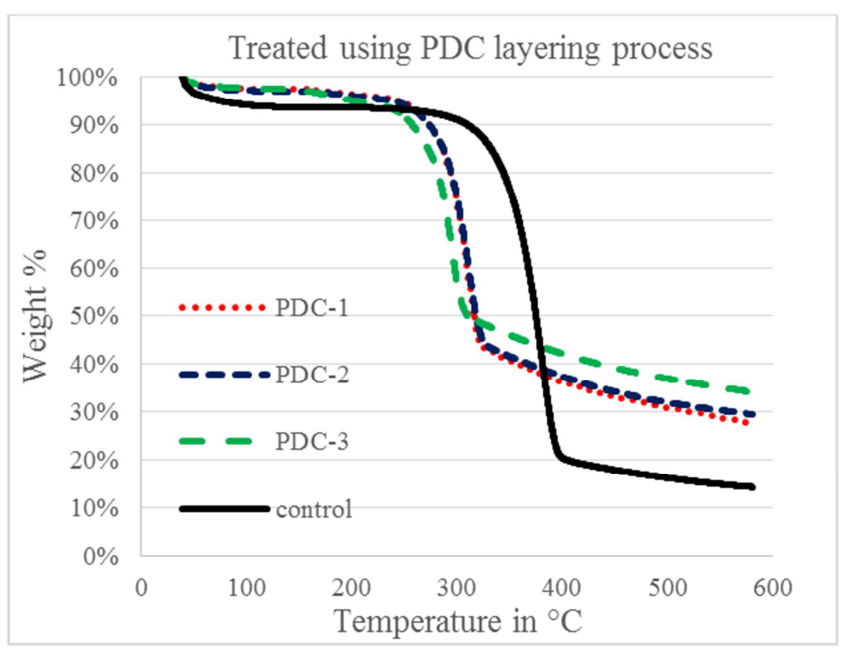

twill (untreated cellulose) fabric. The initial stage (slow weight loss) was found between $100-120^{\circ} \mathrm{C}$ (dehydration), the main stage (rapid weight loss) between $320-375^{\circ} \mathrm{C}$, and the final stage, which is the decomposition of remaining char formed in the main stage (slow weight loss) after $400^{\circ} \mathrm{C}[29,30]$. During the main stage, oxidative decomposition of the products occurred. This involved the creation of carbon monoxide (CO) and carbon dioxide $\left(\mathrm{CO}_{2}\right)$, formation of carboxyl and carbonyl groups, and development of carbonaceous residue. Research has shown that phosphorus additives decrease the onset temperature of treated cellulose in the second stage by 50 $150^{\circ} \mathrm{C}[17,31]$.

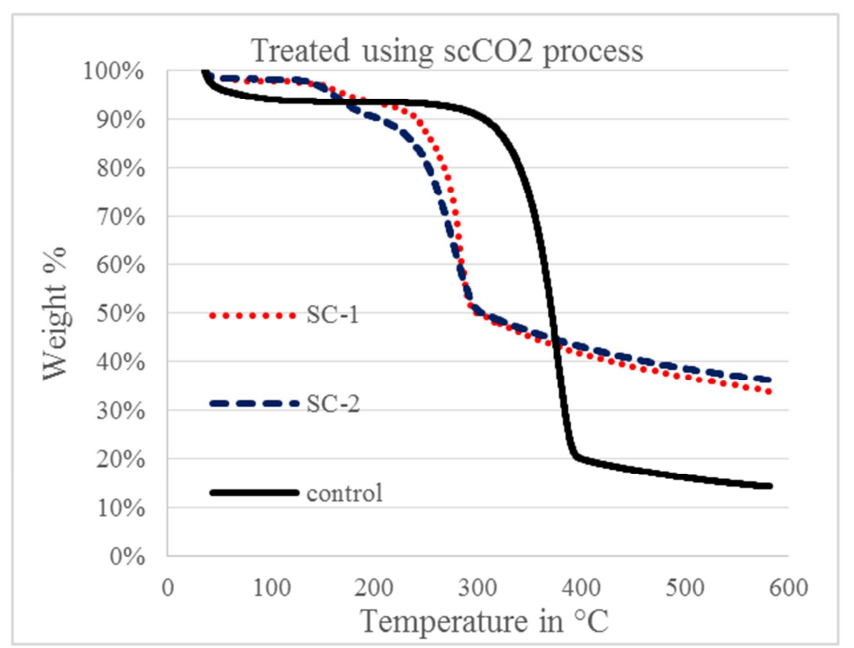

Figure 1. Degradation thermogram curves of the untreated control and treated cotton fabrics coated with PDC layer process (PDC-1, PDC-2, and PDC-3) and $\mathrm{ScCO} 2$ process (SC-1 and $\mathrm{SC}-2)$.

Casein/urea/DAP formulations provided a significantly lower decomposition temperature for cellulose. The onset of degradation temperature for casein/urea/DAP treated, PDC-1, PDC-2 and PDC-3, fabric samples was ranged between 278.9-288. $2^{\circ} \mathrm{C}$, which was $51.8-42.5^{\circ} \mathrm{C}$ lower than untreated fabrics. The onset temperatures for $\mathrm{scCO} 2$ fabrics sample, SC-1 and SC-2, were $250.5-268.8^{\circ} \mathrm{C}$, which were comparable to the onset temperatures of $278.9-288.2^{\circ} \mathrm{C}$ for PDC treated fabrics. The cause of this may be the acceleration of fabric degradation because of the in-situ formation of phosphonic acid derivatives. The onset of degradation temperature range between $250.5-268.8^{\circ} \mathrm{C}$ resulted from the liberation of water and ammonia by the phosphorylation chemical reaction [32]. The pyrolysis system was also quenched as cellulose dehydration was catalyzed by the byproduct of phosphoric acid. At the lower temperature, the decomposition reactions became slow and produced more stable char. Overall, SC-1 and SC-2 fabric samples yielded high char during the thermal degradation process.

As the add-on of the PDC samples increased from 6.1 to $9.5 \mathrm{wt} \%$, increases in char yield were observed from 26.9$33.1 \%$ and decreases in onset temperature were observed from $288.2-278.9^{\circ} \mathrm{C}$. These results support an add-on threshold of PDC-1 and PDC-2; lower add-on values did not provide effective flame retardancy. Greater add-on of PDC-3 had a char yield of $33.1 \%$, and an on-set temperature of $278.9^{\circ} \mathrm{C}$. ScCO2 treated fabrics with a 14.6 and $19.7 \mathrm{wt} \%$ add-on presented char yields of 33.8 and $36.1 \%$, when compared to PDC treated fabrics with char yields of 26.9$33.1 \%$. The char amount at $600^{\circ} \mathrm{C}$ for all treated fabric was $26.9-36.1 \%$, more than double that of untreated fabric. The chars shielded the fabric against heat and flame spread because they generated thermally stable cohesive phases. These phases had decomposition temperatures that exceeded the temperatures of the oxidizing zones of flames. In addition, these chars were intumescing, so they foamed and released gases that decreased flammability. It is crucial to create flame-retardants that promote intumescing and char formation.

\subsection{Microscale Combustion Calorimeter (MCC)}

MCC measures the rate which the heat of fuel gasses is released from a solid under inert conditions [33]. HRR (heat release rate) versus temperature of the untreated control fabric and casein/urea/DAP treated fabrics are shown in Figure 2. The flammability parameters, heat release combustion (HRC), peak heat release rate (pHRR), total heat release (THR), and temperature of maximum of heat release combustion $\left(T_{\max }\right)$, were computed and are presented in Table 2. 
Table 2. Microscale combustion calorimetry (MCC) data of untreated control and treated cotton fabrics coated with PDC layer process (PDC-1, PDC-2, and $P D C-3$ ) and SCCO2 process (SC-1 and SC-2), (reported value is the average from three observations).

\begin{tabular}{llllll}
\hline Sample symbol & Add-ons (wt\%) & HRC (J/gK) & pHRR (W/g) & THR (KJ/g) & T $_{\max }\left({ }^{\circ} \mathbf{C}\right)$ \\
\hline Control & 0 & 270.0 & 269.4 & 12.0 & 390.0 \\
PDC-1 & 6.1 & 163.7 & 163.7 & 4.73 & 314.2 \\
PDC-2 & 6.3 & 156.0 & 155.8 & 4.70 & 312.8 \\
PDC-3 & 9.5 & 132.7 & 132.4 & 3.27 & 302.2 \\
SC-1 & 14.6 & 113.0 & 113.1 & 2.85 & 291.9 \\
SC-2 & 18.7 & 56.9 & 1.53 & 281.3 \\
\hline
\end{tabular}

The thermal decomposition of the control sample started around $300^{\circ} \mathrm{C}$. The thermal decomposition, as indicated by rising HRC, strengthened as the temperature increased. Then, it attained a maximum point at $390.0^{\circ} \mathrm{C}$ and ended around $420^{\circ} \mathrm{C}$ with an approximate value of $12.00 \mathrm{~kJ} / \mathrm{g}$ in THR. The control exhibited a significantly higher pHRR value of $269.4 \mathrm{~W} / \mathrm{g}$, whereas treated fabrics pHRR values ranged between 56.9$163.7 \mathrm{~W} / \mathrm{g}$. Higher pHRR values indicate an increased amount of heat released during the burning process, which may result from rapid pyrolysis and combustion of treated fabrics [34]. This may account for the sharp HRR profiles of treated fabrics. Generally, as the add-on levels of casein/urea/DAP increased, pHRR, THR, and $\mathrm{T}_{\mathrm{MAX}}$ values decreased. The PDC treated fabrics had a pHRR range of 132.4-163.7 W/g $(6.1,6.3$, and 9.5 $\mathrm{wt} \%$ ), and were much higher compared to the $\mathrm{pHRR}$ range of $56.9-113.1 \mathrm{~W} / \mathrm{g}$ (14.6 and $18.7 \mathrm{wt} \%)$ obtained for scCO2 fabrics. An add-on of $6.1-6.3 \mathrm{wt} \%$ had THR and $\mathrm{T}_{\mathrm{MAX}}$ values of 4.70 -
$4.73 \mathrm{~kJ} / \mathrm{g}$ and $312.8-314.2^{\circ} \mathrm{C}$, respectively. As the add-on increased to $9.5 \mathrm{wt} \%$, the THR and TMAX values decreased to $3.27 \mathrm{~kJ} / \mathrm{g}$ and $302.2^{\circ} \mathrm{C}$, respectively. These values were lower than the THR and $\mathrm{T}_{\mathrm{MAX}}$ values obtained for the control fabric, $12 \mathrm{~kJ} / \mathrm{g}$ and $390^{\circ} \mathrm{C}$, respectively. Supercritical carbon dioxide treated fabrics exhibited a different calorimetric performance. The scCO2 fabrics at $18.7 \mathrm{wt} \%$ add-on had a lower THR value of $1.53 \mathrm{~kJ} / \mathrm{g}$.

All treated fabrics had lower THR, HRC and $\mathrm{T}_{\max }$ values than the untreated control. The protective layer then prevented the cotton fabrics from igniting and reduced the normal thermal degradation of cotton fabrics and structural disintegration of the char to release volatiles and gases. Once the urea had burned, the main material started to burn and gave rise to the second peaks at around $250-320^{\circ} \mathrm{C}$. These peaks on the same shoulder slightly decreased with increasing add-on values from 14.6 to $18.7 \mathrm{wt} \%$.
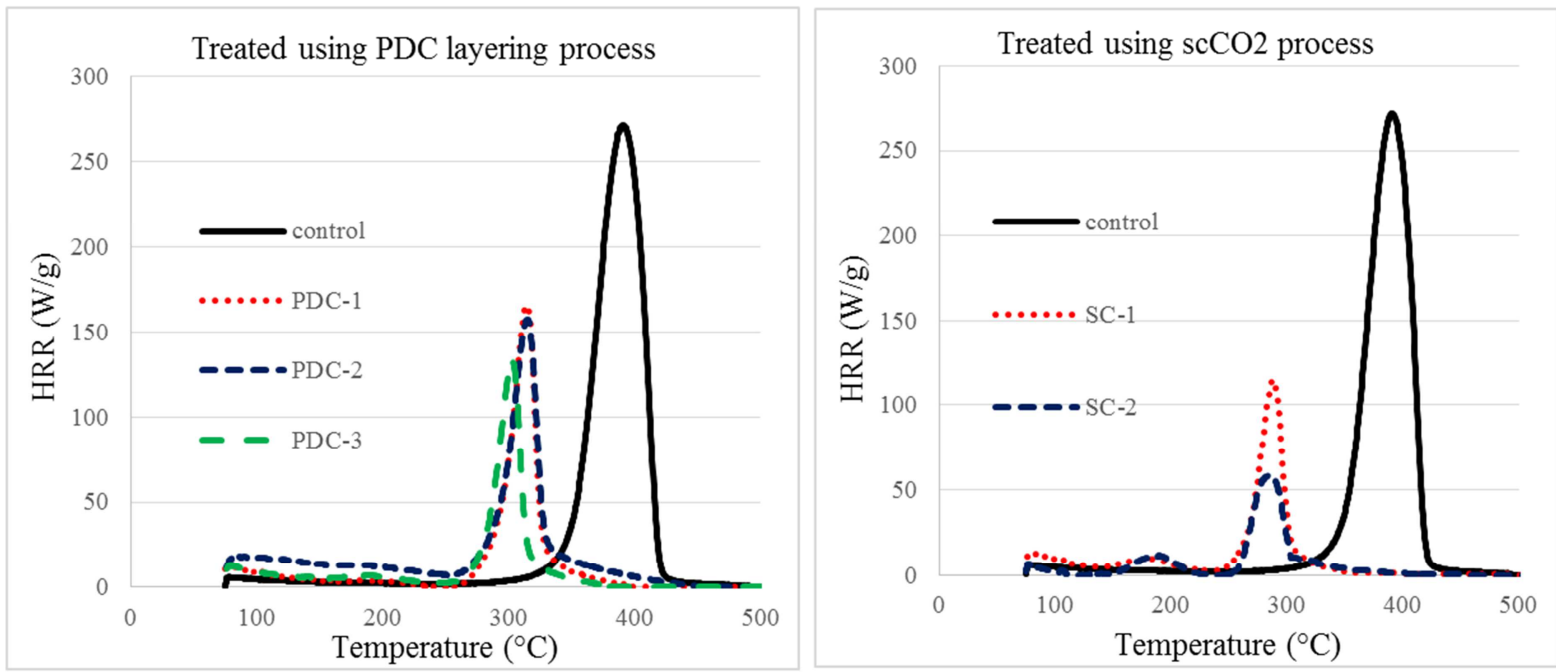

Figure 2. Microscale combustion calorimeter (MCC) graphs of heat release combustion curves for untreated control and treated cotton fabrics coated with $P D C$ layer process (PDC-1, PDC-2, and PDC-3) and SCCO2 process (SC-1 and SC-2).

\subsection{Flame Retardant Properties}

Flammability requirements for all clothing textiles, before sale or introduction into trade, are instituted in the $45^{\circ}$ angle flammability test. The standard offers a consistent method to test textiles, and divides textile products used for clothing into three classes of flammability performance, thus limiting the use of flammable clothing in textiles. During the test procedure, a $16 \mathrm{~mm}(5 / 8 \mathrm{in})$ flame is positioned to touch the bottom of a specimen fixed at a $45^{\circ}$ angle for 10 seconds.
The fabric sample burns its full length, a distance of $127 \mathrm{~mm}$ (5 in), or until the thread that stops the timer is broken. Class 1 and 2 specimens meet the requirements of the standard. Class 3, rapid and intense burning, does not meet the requirements of the standard. Table 3 shows that the untreated control fabric was completely burned and was totally consumed during the test. The test also showed the effectiveness of PDC treated (PDC-1, PDC-2, and PDC-3) and $\mathrm{scCO} 2$ treated samples (SC-1 and SC-2). The control fabric burned for a total of $77 \mathrm{~s}$, which was expected due to 
the release of flammable gasses upon combustion of cotton fabric. The PDC treated fabric with an add-on of 6.1 and 6.3 $\mathrm{wt} \%$ burned for a total of 59-69 $\mathrm{s}$ and resulted in a reduced burning time compared to the control. As the add-on increased to $9.5 \mathrm{wt} \%$, the fabric was self-extinguished. Treated fabrics with an add-on of $9.5 \mathrm{wt} \%$ and higher did not ignite. For $\mathrm{scCO} 2$ treated fabrics, add-ons of 14.6 and $18.7 \mathrm{wt} \%$ were self-extinguishing.

During the vertical testing, there was no occurrence of melting or dripping of the burning fabrics. Moreover, the after-glow burning did not happen for any add-on levels upon the removal of the flame. As can be seen in Table 3, the low add-ons (6.1 and $6.5 \mathrm{wt} \%)$ treated fabrics are more combustible than the higher add-on fabrics. Although in the first case the fabrics burn the entire length of $30 \mathrm{~cm}$, their after-flame time is longer than that of the control fabric. Among the burned treated fabrics (PDC-1 and PDC-2), the higher the add-on they have, the longer after-flame time they exhibit. Obviously, all burned treated fabrics still hold up, while the controls are destroyed. Overall, PDC treated fabric,
$9.5 \mathrm{wt} \%$, and $\mathrm{scCO} 2$ treated fabrics add-ons of 14.6 and $18.7 \mathrm{wt} \%$ pass the vertical flame test with small char length and char width $(<50 \%$ of the original length of $30 \mathrm{~cm}$ and the after-flame and after-glow times were between 0 and 2 s), while the rest of the samples fail the test with their over-thelimit values.

Limiting oxygen index (LOI) values represent the minimum amount of oxygen, in an atmosphere of oxygen and nitrogen, needed to support a candle like flame during burning for 2 inches or 3 minutes, whichever comes first. The ease of ignition is defined as the capacity with which ignition of a material occurs under given conditions of oxygen concentration. A flammable textile has an LOI value below $21 \%$ and a flame-retardant textile has an LOI value of $26 \%$ or higher. Given in Table 3 are the LOI values of untreated fabrics, $18 \%$ (average) oxygen in nitrogen. PDC treated fabrics with an add-on of $6.1,6.3$ and $9.5 \mathrm{wt} \%$ presented LOI values of 22,23 , and $29 \%$, respectively. For scCO2 treated fabrics, add-ons of 14.6 and $18.7 \mathrm{wt} \%$ were slow burning and self-extinguishing with high LOI values of 35 and $40 \%$.

Table 3. Summaries of LOI, $45^{\circ}$ angle (ASTM D-1230-01) and vertical (ASTM D-6413-11) flammability tests for different add-ons (wt\%) of PDC and ScCO2 treated fabrics. All values for $45^{\circ}$ angle and vertical tests are averages from two observations on the same fabric type.

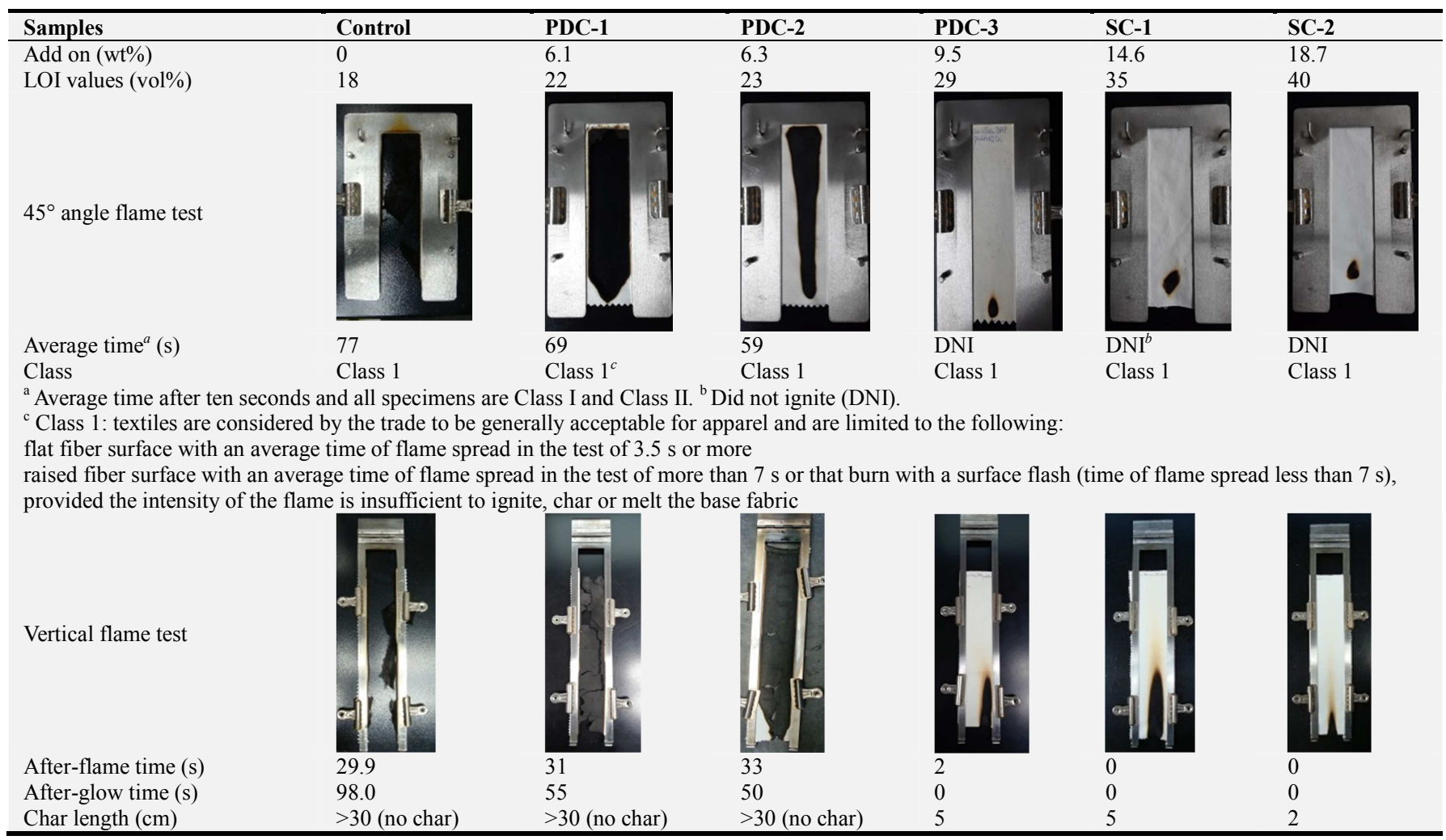

\subsection{Scanning Electron Microscope (SEM)}

Scanning electron microscopy images of the burned control fabric and burned region of $18.7 \mathrm{wt} \%(\mathrm{scCO} 2$ treated $\mathrm{SC}-2)$ are shown in Figure 3. All samples were obtained after vertical flammability testing. The burned samples were collected from the area where the flame contacted directly with the fabrics and turned the fabrics to char. Under the influence of flame and heat, the shape and the appearance of the control untreated fibers were completely destroyed. The scCO2 treated fibers, however, exhibited a noticeable change in surface morphology and developed particulate-like aggregates on the surface, indicating a successful deposition of casein/urea/DAP. When the treated fabrics are burned, the FRs decompose first to release the nonflammable gasses that are trapped under the coated layer of the chemicals. The results of this trapping are the swollen blisters on each fiber. After a long burning, more 
gas is released that inflates these swollen areas. The introduction of casein/urea/DAP to the fabrics increases the thermal stability of the fibers during the burning, while the burned control is destroyed completely to ashes. The occurrence of the swollen fibers and blisters on the treated and burned fabric surfaces introduces evolved decomposition products to the adjacent flame, which may in turn modify the respective FR effectiveness depending on whether they are
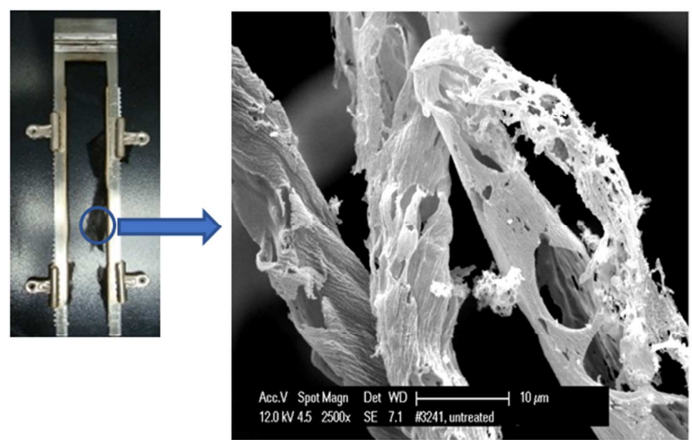

flammable or not. These types of protective coatings were observed in earlier studies where the burned surface morphology was linked to the FR ability of the phosphoramidate and phosphorus-nitrogen containing FRs [35]. This result indicates that the structure of the chars on the surface of each fiber provides the resistance of heat transfer and retards the degradation of underlying materials effectively. Therefore, combustion cannot be self-sustained.
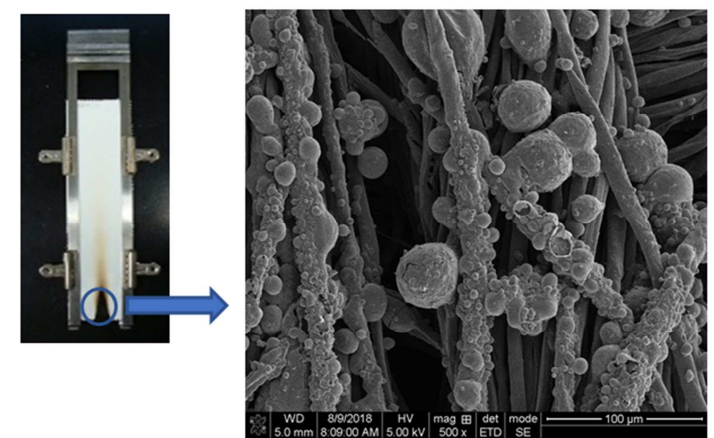

Figure 3. SEM Micrographs of untreated control (left) and highest (18.7wt\%) add-on (SC-2) fabrics after burn (right) at a magnification between 500x-2500x.

\section{Conclusions}

Eco-friendly supercritical carbon dioxide ( $\mathrm{scCO} 2)$ and pad-dry-cure (PDC) layering processes were used when casein was introduced into the urea and diammonium phosphate (DAP) flame retardant chemical system. There are no reported methods for creating casein containing flame retardant cotton fabrics using scCO2. As a result of this study, economic inorganic flame-retardant finishing treatments based on urea and diammonium phosphate have been applied to cotton fabrics using $\mathrm{scCO} 2$ and $\mathrm{PDC}$ methods (for comparison). Tests performed on TGA showed that char yield for scCO2 treated fabric samples is higher than that of PDC samples, and $\mathrm{scCO} 2$ samples provided lower onset of degradation than PDC ones. Fabrics treated with 14.7 and $18.6 \mathrm{wt} \%$ of scCO2, and $9.5 \mathrm{wt} \%$ PDC passed the vertical flammability test. In the MCC experiments, a better reduction in heat of combustion was shown through the lower values found for THR, HRC and $\mathrm{T}_{\max }$ for all $\mathrm{scCO} 2$ treated with casein/urea/DAP fabrics when compared to PDC treated with casein/urea/DAP fabric. All the casein/urea/DAP treated fabrics above $9.5 \mathrm{wt} \%$ add on showed a substantial resistance to flame application during limiting oxygen index (LOI), $45^{\circ}$ angle, and vertical flammability tests. Casein/urea/DAP treated samples using scCO2 passed vertical flame test at the levels of 14.7 and 18.6 add-ons (wt\%), and all samples are regarded as class I (flame retardant) fabrics after $45^{\circ}$ angle testing. $\mathrm{scCO} 2$ treated fabric samples had higher LOI values when compared with PDC samples. SEM micrographs indicated treated fabrics could form a protective layer, which prevented the fabric from being burned completely. scCO2 treated samples formed a layer wrapping around the cotton fibers to protect them from being destroyed by heat and flame. The superior action of scCO2 samples could be attributed to the ability to degrade into more gas products arising from the nitrogen atom attached to the phosphorus in phosphorus moiety. While the differences observed in the performance of the treated fabrics were due to the sample preparation methods, more studies will need to be performed to determine why a lower performance in PDC method was observed compare with scCO2 method. In conclusion, both processing methods are promising for applications of flame retardants to cotton textiles, however scCO2 method shows a more beneficial advantage in FR performances. Further studies on durability properties using standard Laboratory Practice for Home Laundering will be carried out and presented in a future publication.

\section{Acknowledgements}

We acknowledge support from the U. S. Department of Agriculture. The authors would like to express gratitude to Jade Smith for all the experiments of TGA, MCC, flame tests and data collection.

\section{References}

[1] Lewin, M. and Weil, E. D. in "Mechanisms and modes of action in flame retardancy of polymer", 1st ed., Cambridge and Florida: Woodhead Publishing Ltd and CRC Press LLC (2001).

[2] Schartel, B. Phosphorus-based Flame Retardancy Mechanisms -Old Hat or a Starting Point for Future Development? Materials, 2010. Vol. 3, 4710-4745.

[3] Braun, U., Bahr, H., Sturm, H. and Schartel, B. Flame retardancy mechanisms of metal phosphinates and metal phosphinates in combination with melamine cyanurate in glass-fiber reinforced poly (1,4-butylene terephthalate): the influence of metal cation. Polymers Advanced Technologies, 2008. Vol. 19, 680-692. 
[4] Braun, U. and Schartel, B. Flame retardancy mechanisms of aluminium phosphinate in combination with melamine cyanurate in glass-fibre-reinforced poly (1, 4-butylene terephthalate). Macromolelular Materials and Engineering, 2008. Vol. 293, 206-217.

[5] Levchik, S. V. and Wilkie, C. A. Char Formation. In A. F. Grand \& C. A. Wilkie (Eds.), Fire Retardancy of Polymeric Materials (pp. 171-215). New York: Marcel Dekker (2000).

[6] Braun U., Balabanovich A. I., Schartel B., Knoll U., Artner J., Ciesielski M., Döring M., Perez R., Sandler J. K. W., Altstädt V., Hoffmann T. and Pospiech D. Influence of the oxidation state of phosphorus on the decomposition and fire behaviour of flame-retarded epoxy resin composites. Polymer. 2006. Vol. $47,8495-8508$

[7] Levchik S. V. and Weil E. D. Thermal decomposition, combustion and flame - retardancy of epoxy resins - a review of the recent literature. Polymer. International. 2004. Vol. 53, 1901-1929.

[8] Peng, H. Q., Wang, D. Y., Zhou, Q. and Wang, Y. Z. An S-and P-containing flame retardant for polypropylene. Chinese Journal of Polymer Science. 2008. Vol. 26, 299-309.

[9] Younis, A. A., El-Nagar, K. and Nour, M. A. Part I: Characterization of flammability behavior of polyester fabric modified with sol-gel. Intenational Journal of Chemistry. 2013. Vol. 5, 38-46.

[10] Deo H. T., Patel N. K., Patel B. K. Eco-friendly Flame Retardant (FR) Pet Fibers through P-N Synergism. Journal of Engineering Fibers and Fabrics. 2008. Vol. 3, 23-38.

[11] Tsafack, M. J. and Levalois-Grützmacher, Towards multifunctional surfaces using the plasma-induced graftpolymerization (PIGP) process: Flame and waterproof cotton textiles. Journal of Surface and Coatings Technology. 2007. Vol. 201, 5789-5795.

[12] Carosio, F., Blasio, A. D., Cuttica, F., Alongo, J. and Malucelli, G. Flame retardancy of polyester and polyestercotton blends treated with caseins. Industrial \& Engineering Chemistry Research. 2014. Vol. 53, 3917-3923.

[13] Alongi, J., Carletto, R. A., Bosco, F., Carosio, F., Blasio, A. D., Cuttica, F., Antonucci, V., Giordano, M. and Malucelli, G. Caseins and hydrophobins as novel green flame retardants for cotton fabrics. Polymer degradation and stability. 2014. Vol. 99, 111-117.

[14] Parikh, D., Calamari, T. A. and Peterson, D. B. FR/Resilient Perpendicular-Laid Nonwovens Containing Cotton. AATCC Review. 2002. Vol. 2, 33-37.

[15] Weil, E. D. and Levchik, S. V. Flame retardants in commercial use or development for textiles. Journal of Fire Science. 2008. Vol. 26, 243-281.

[16] Gaan, S. and Sun, G. Effect of phosphorus flame retardants on thermo-oxidative decomposition of cotton. Polymer Degradation and Stability. 2007. Vol. 92, 968-974.

[17] Nguyen, T., Chang, S., Condon, B., Slopek, R., Graves, E., Yoshioka-Tarver, M. Structural effect of phosphoramidate derivatives on the thermal and flame retardant behaviors of treated cotton cellulose. Industrial \& Engineering Chemistry Research. 2013. Vol. 52, 4715-4724.

[18] Yoshioka-Tarver, M., Condon, B. D., Santiago Cintrón, M., Chang, S., Easson, M. W., Fortier, C. A., Madison, C. A., Bland, J. M.,
Nguyen, T. D. Enhanced flame retardant property of fiber reactive halogen-free organophosphonate. Industrial \& Engineering Chemistry Research. 2012. Vol. 51, 11031-11037.

[19] Frank, S. G. Inclusion compounds. Journal of Pharmaceutical Sciences 1975. Vol. 64, 1585-1604.

[20] Zeronian, S. H., Intercrystalline Swelling of Cellulose. In Cellulose Chemistry and Its Applications; Nevell, T. P., Zeronian, S. H., Eds.; Ellis Horwood Limited Inc.: Chichester, UK, 1985, pp138-180.

[21] Yin, C. Y., Li, J. B., Xu, Q., Peng, Q., Liu, Y. B. and Shen, X. Y. Chemical modification of cotton cellulose in supercritical carbon dioxide: Synthesis and characterization of cellulose carbamate. Carbohydrate Polymers. 2007. Vol. 67, 147-154.

[22] Kraft, G., Muss, C., Adelwohrer, C., Roder, T. and Rosenau, T. Treatment of cellulosic fibers with supercritical carbondioxide. Lenzinger Berichte. 2004. Vol. 83, 117-121.

[23] Tsioptsias, C. and Panayiotou, C. Thermal stability and hydrophobicity enhancement of wood through impregnation with aqueous solutions and supercritical carbon dioxide. Journal of Materials Science. 2011. Vol. 46, 5406-5411.

[24] Ginneken, L. V. and Weyten, H. "Particle formation using supercritical carbon dioxide," in Carbon Dioxide Recovery and Utilization, M. Aresta, Ed. Dordrecht, The Netherlands: Kluwer Academic Publishers, 2003, pp. 123-136.

[25] Filardo, G., Galia, A. and Giaconia, A. "Modification of polymers in supercritical carbon dioxide," in Carbon Dioxide Recovery and Utilization, M. Aresta, Ed. Dordrecht, The Netherlands: Kluwer Academic Publishers, 2003, pp. 197-207.

[26] Minimum oxygen concentration to support candle-like combustion, 2009, American Society for Standards and Testing, ASTM D-2863-09.

[27] Standard test method for flame resistance of textiles, 2001, American Society for Standards and Testing, ASTM D-1230-01.

[28] Standard test method for flame resistance of textiles, 2001, American Society for Standards and Testing, ASTM D-6413-11.

[29] Muralidhara, K. S. and Sreenivasan, S. Thermal degradation and burning behaviour of cellulose based and cellulose-silk blended upholstery fabrics. Journal of Scientific and Industrial Research. 2010. Vol. 69, 879-885.

[30] Wang, S., Liu, Q., Luo, Z., Wen, L. and Cen, K. Front. Mechanism study on cellulose pyrolysis using thermogravimetric analysis coupled with infrared spectroscopy. Frontiers Energy and Power Engineering in China. 2007. Vol. 1, 413-419.

[31] Faroq, A. A., Price, D., Milnes, G. J., and Horrocks, A. R. Thermogravimetric analysis study of the mechanism of pyrolysis of untreated and flame retardant treated cotton fabrics under a continuous flow of nitrogen. Polymer Degradation and Stability. 1994. Vol. 44, 323-333.

[32] Hendrix, J. E., Bostic Jr., J. E., Olson, E. S., and Barker, R. H. Pyrolysis and combustion of cellulose. I. Effects of triphenyl phosphate in the presence of nitrogenous bases. Journal of Applied Polymer Science. 1970. Vol. 14, 1701-1723.

[33] Yang, C. Q. and He, Q. Applications of micro-scale combustion calorimetry to the studies of cotton and nylon fabrics treated with organophosphorus flame retardants. Journal of Analytical and Applied Pyrolysis. 2011. Vol. 91, 125-133. 
[34] Benin, V., Durganala, S., Morgan, A. B. Synthesis and flame retardant testing of new boronated and phosphonated aromatic compounds. Journal of Materials Chemistry. 2012. Vol. 22, $1180-1190$.
[35] Nguyen, T. D., Chang, S., Condon, B. D., Slopek, R. P. Synthesis of a novel flame retardant containing phosphorusnitrogen and its comparison for cotton fabric. Fibers and Polymers. 2012. Vol. 13, 963-970. 